Para citar este artículo: López Villafranca, P. (2019). Estudio de casos de la ficción sonora en la radio pública, RNE, y en la plataforma de podcast del Grupo Prisa en España. Anuario Electrónico de Estudios en Comunicación Social "Disertaciones", 12(2), 65-78. Doi: http://dx.doi.org/10.12804/revistas.urosario.edu.co/ disertaciones/a.6547

\title{
ESTUDIO DE CASOS DE LA FICCIÓN SONORA EN LA RADIO PÚBLICA, RNE, Y EN LA PLATAFORMA DE PODCAST DEL GRUPO PRISA EN ESPAÑA
}

\section{Cases Study of the Sound Fiction on Public Radio, RNE, and on the Podcast Platform of Prisa Group in Spain}

\section{Estudo de casos da ficção sonora na rádio pública, RNE, e na plataforma de podcast do Grupo Prisa na Espanha}

Paloma López Villafranca, Universidad de Málaga (España)

pallopvil@uma.es

Recibido: 15 de febrero de 2018

Aprobado: 22 de mayo de 2018

\section{RESUMEN}

El cambio en el hábito de consumo de la radio con las nuevas tecnologías y la aparición de creaciones de audio digitales con un formato diferente a los espacios de radio tradicionales han propiciado la proliferación del podcast de ficción en España. Es el caso de los podcasts Negra y criminal y El gran apagón de la plataforma Podium Podcast (Prisa), y la irrupción de formatos novedosos como Tiempo de valientes y Carlos de Gante de RNE. El objetivo de esta investigación es realizar un análisis comparativo de estos nuevos formatos. Para ello hicimos un análisis de contenido de estos espacios de ficción de la plataforma española Podium Podcast y de los formatos transmedia de la 


\section{DISERTACIONES}

ESTUDIOS

emisora RNE durante la primera temporada de emisión 2016-2017. Comprobamos que los podcasts de RNE cumplen la función de complementar las tramas de las series televisivas, el núcleo central del transmedia, con breve duración y basados más en pensamientos y narración que en la acción. Por otra parte, los formatos de Podium, que siguen la fórmula estadounidense con mayor duración, incluyen elementos narrativos que rompen con el tradicional radioteatro y prima la acción frente al relato.

Palabras clave: ficción sonora, podcast, transmedia, radio, España.

\section{ABSTRACT}

The changes in listeners habits with new technologies and the appearance of digital audio creations with a different format from traditional radio spaces have increased the fictional podcast. Such is the case of Negra y criminal and El gran apagón from Podium Podcast (Prisa) and the irruption of novel formats like Tiempo de valientes and Carlos de Gante, from RNE. The objective of this research is to carry out a comparative analysis of these new formats. To this end, we analyze these formats from Podium Podcast and RNE in the season 2016-2017. The RNE podcast complements the plot of the television series, the central nucleus of transmedia, with a brief duration and bases more on thoughts and narration than on action. On the other hand, Podium formats, which follow the American formula with longer duration, include narrative elements that break with the traditional radio theatre, in which action takes a prominent role over narration.

Keywords: Sound fiction, podcast, transmedia, radio, Spain.

\section{RESUMO}

A mudança no hábito de consumo da rádio com as novas tecnologias e a aparição de criações de áudio digitais com um formato diferente aos espaços de rádio tradicionais, têm propiciado a proliferação do podcast de ficção na Espanha. No caso dos podcast Negra y Criminal e El Gran Apagón da plataforma Podium Podcast (Prisa) e a irrupção de formatos inovadores como Tiempo de Valientes e Carlos de Gante, de RNE. O objetivo desta pesquisa é realizar uma análise comparativa destes novos formatos. Para isto realizamos uma análise de conteúdo destes espaços de ficção da plataforma espanhola Podium Podcast, e dos formatos transmedia de RNE durante a primeira temporada de emissão 2016-2017. Comprovamos que os podcast de RNE cumprem a função de complementar as tramas das séries televisivas, o núcleo central da transmedia, com breve duração e baseados mais em pensamentos e narração que na ação. Por outra parte, os formatos de Podium, que seguem a fórmula estadunidense com maior duração, incluem elementos narrativos que rompem com a tradicional rádio teatro e prima a ação frente ao relato.

Palavras-chave: ficção sonora, podcast, transmedia, rádio, Espanha. 


\section{DISERTACIONES}

ESTUDIOS

\section{Introducción}

Las transformaciones tecnológicas y, como consecuencia, el cambio de hábito de consumo de medios de las nuevas generaciones ha propiciado que estos nuevos oyentes y los tradicionales se decidan por el consumo del podcast frente a la radio tradicional. La 3a Ola del EGM desde el 6 de septiembre al 14 de noviembre de 2017 confirma que el streaming supera a la onda media en la escucha de radio (AIMC, 2017). La radio tradicional, sintonizada en AM O FM es cada vez una realidad que se reserva a momentos muy puntuales, ya que la escucha tiene lugar de forma más habitual en el Pc o el teléfono móvil. Albarrán et al. (2007) consideran que la escucha de la radio tradicional solo se produce en situaciones muy concretas (principalmente en el coche) y como fuente de información de acontecimientos de actualidad. Escuchamos las noticias de camino al trabajo o a la salida de este, o música cuando viajamos en el automóvil. La aparición de internet se relacionó con la crisis del medio radiofónico en la etapa inicial. Muchos autores consideraron que internet acapararía la capacidad de inmediatez del medio. Para autores como Rodero (2005), la crisis se centraba en los contenidos y en fórmulas creativas para llegar a los oyentes, a favor de la información de forma económica y sencilla. Pero lo cierto es que en los últimos cinco años el podcast se impone como tendencia y el consumo de los programas a la carta es una realidad, en la que ya incluso el Estudio General de Medios en España aprecia la necesidad de su evaluación y medición a través de las descargas de los usuarios.

Para López Vidales et al. (2015), los modelos tradicionales de radio han cambiado, debido fundamentalmente a la preferencia de los usuarios "hacia estructuras de relación comunicativa más abiertas, de complicidad permanente, instantaneidad en la comunicación, contenidos compartibles de usar y tirar, información adicional en imágenes, experiencias, transmedia, radio a la carta, etc." (p. 49).

Hay diversos estudios, entre los que destacan los de López Vidales et al. (2011), que confirman que los jóvenes entre 14 y 24 años son los que menos escuchan el medio radiofónico por su carácter de 'nativos digitales', acostumbrados a recibir de forma instantánea información (p. 47). Los autores detectan la necesidad de pensar una radio para los jóvenes que favorezca la interactividad y ofrezca variedad de contenidos. Es la ficción la que ha logrado atrapar a las nuevas generaciones en el formato radiofónico o en plataformas de podcast, como la de reciente creación Podium Podcast, del grupo de comunicación español Prisa. Pero no solo los nuevos oyentes, los tradicionales también aprecian en la web de las emisoras la necesidad de descubrir estos formatos. El modelo de distribución de Netflix cambia la forma de consumir el audiovisual y la fidelidad de la audiencia, y, para Moreno Cazalla (2017), "es la ficción la que está atrayendo a la audiencia de Podium Podcast, al menos según las cifras internas y en valoraciones en la plataforma" (p. 354).

Según Rodero (2004), los géneros de ficción "son aquellas estructuras radiofónicas que sustentan su materia prima en la ficción y cuya función principal es el entretenimiento". La autora distingue entre los géneros de monólogo: cuento, relato radiofónico; los géneros de diálogo: sketch, representación y radioteatro; y, finalmente, géneros mixtos: adaptación literaria y recreación. El podcast de ficción que aparece como formato novedoso y con narrativa similar a la de las series televisivas se presenta como un producto de menor duración que cualquier espacio radiofónico del mismo género, entre los 3 y los 30 minutos, se descarga de forma seriada como los programas de 


\section{DISERTACIONES}

ESTUDIOS

El papel del sonido en la comunicación: contribución, funciones y efectos

ISSN: $1856-9536$

Doi: http://dx.doi.org/10.12804/revistas.urosario.edu.co/disertaciones/a.6547

Volumen 12, Número 2 / Julio-diciembre 2019

Versión PDF para imprimir desde

http://revistas.urosario.edu.co/index.php/disertaciones

radio y engancha a la audiencia que puede consumir dichos productos sonoros a la carta en el momento que considera más oportuno.

Por otra parte, la ficción ha logrado que la radio se incorpore con éxito en España al universo transmedia y que sea capaz de captar nuevos adeptos que no tenían hábitos de escucha. Tal y como afirma Scolari (2013), "las audiencias se han vuelto líquidas y los consumidores ya no se conforman con acceder a los contenidos desde una sola pantalla, las nuevas generaciones tienen que ver cosas diferentes, en diferentes medios y con diferentes modalidades de consumo" (p. 221).

\section{El éxito del podcast y la aparición de la plataforma Podium Podcast en España y Latinoamérica}

En 2014 la irrupción de Serial, un podcast cuyo objetivo era reabrir la investigación de un crimen ocurrido quince años atrás de una adolescente de origen surcoreano en Baltimore, marcó un antes y un después en el éxito del podcast radiofónico en Estados Unidos. "Serial propuso un híbrido entre la crónica periodística y el entretenimiento radiofónico. La fuerza de su debut radicó, precisamente, en tratar sobre un hecho real dramático, pero narrativamente imperfecto, de ahí la ausencia de recursos para conseguir la suspensión de incredulidad" (Linares \& Neira, 2017, p. 75). Lo que empezaría con objetivo periodístico se acabó convirtiendo en un producto totalmente innovador, imprevisible, llegando a transformarse en una ficción interactiva y transmedia. Según estos autores, fue su alto número de descargas y su influencia social en algunos medios los que hacen que 2014 se considere el año del renacimiento del podcast.

En España, el podcast deja de ser el gran desconocido gracias a la radio a la carta y sobre todo a espacios de ficción. RNE reintrodujo de nuevo la ficción gracias a programas como Ficción sonora, que recupera el radioteatro. Desde el inicio de la radio comercial, la ficción ha acompañado al oyente y ha sido una parte indispensable de la programación. Entre los años cuarenta y cincuenta el radioteatro se convierte en el espacio estrella en todas las emisoras durante un período en el que es el medio por antonomasia. Las compañías de actores, como las creadas por Antonio Calderón en 1942, interpretan adaptaciones literarias basadas en grandes obras de Calderón, Pirandello o Cervantes (Balsebre, 1999, p. 58). Radio Nacional de España o la Cadena ser se erigen como las emisoras que llevan este género a su máxima expresión en España en la década de los cincuenta y sesenta. Encontramos las famosas novelas radiofónicas o las obras de teatro dramatizadas, que desaparecieron de antena hace unas décadas y que desde 2011 han vuelto a cobrar protagonismo en programas como el ya mencionado Ficción sonora de RNE. Pero el Grupo Prisa da un paso más y en su afán por conquistar a nuevos oyentes y difundir la ficción radiofónica crea Podium Podcast. Prisa Radio es un grupo internacional al que pertenecen distintas emisoras en Latinoamérica, Estados Unidos y España. La creación de esta plataforma supone un salto cualitativo en la gestión de contenidos que se producen tanto en España como en países como México, Argentina, Chile y Colombia.

Tal y como apunta Rodríguez Pallares (2017), la iniciativa navideña de la Cadena sER, Cuento de Navidad en 2013, supuso nuevamente la apuesta por el radioteatro, aunque en 2011 se gestaría esta tendencia hacia la ficción sonora con la emisión de la obra Las bicicletas son para el verano. Podium Podcast es "una red global de podcast 


\section{DISERTACIONES}

ESTUDIOS

El papel del sonido en la comunicación: contribución, funciones y efectos

ISSN: $1856-9536$

Doi: http://dx.doi.org/10.12804/revistas.urosario.edu.co/disertaciones/a.6547

Volumen 12, Número 2 / Julio-diciembre 2019

Versión PDF para imprimir desde

http://revistas.urosario.edu.co/index.php/disertaciones

en español, tal y como se explica en su sitio web, que conjuga tecnología con innovación narrativa y reutilización de fondos de archivo" (Rodríguez Pallares, 2017, p. 92). Y es ahí donde reside su éxito y donde se aprecia la importancia de la narrativa y la innovación de su fórmula, que intenta romper esquemas y atraer a nuevos oyentes.

\section{La innovación de RTVE en el formato transmedia sonoro en España}

A través de la narrativa transmedia se produce un proceso donde los elementos de una ficción se dispersan en diversos canales de distribución y crean una experiencia única y coordinada (Jenkins, 2007, p. 3). Estamos ante lo que Phillips (2012) denomina "hot new thing. It is the realm of deep experiences and completely inmersive stories, and it can evoke emotions that simply can't be replicated in a single novel or film" (p. 5). En todo este proceso, de compartir experiencias inmersivas en distintos medios, la radio parecía no encontrar su sitio. Según Scolari (2013), "si bien la televisión sigue siendo el medio más visto, la radio había abandonado el segundo lugar en favor de los ordenadores personales” (p. 219). La forma de consumir los medios cambia y la utilización de los aparatos receptores tradicionales queda obsoleta para los nuevos usuarios. Pero la nueva audiencia tiene aún mucho por descubrir de las posibilidades de la narrativa radiofónica y a ello contribuyen las nuevas tecnologías. Para Jenkins (2006), "el público, con poder gracias a estas nuevas tecnologías, ocupando un espacio en la intersección entre los viejos y los nuevos medios, exige el derecho a participar en la cultura" (p. 34).

Es básico comprender, tal y como afirma Scolari (2013), que las audiencias se han vuelto 'líquidas'. Los consumidores solían estar frente al televisor, viendo los programas a la misma hora, un fenómeno en vías de extinción. Según el autor, aunque seguimos siendo grandes consumidores de contenidos audiovisuales, los vemos en una amplia variedad de dispositivos y pantallas. Las nuevas generaciones tienden a ver cosas diferentes, en diferentes medios y con diferentes modalidades de consumo (en vivo, streaming, descargas, etc.). Cuando irrumpió internet en el escenario mediático, la radio seguía sin transformarse en las emisoras convencionales, ya que la narrativa transmedia radiofónica aún se encuentra en fase experimental en España.

Existen antecedentes de la radio transmedia española. Según Fernández Aldana (2015), la Escuela de Radio TEA FM de Zaragoza ha experimentado desde 2008 con nuevos formatos de radio transmedia, que le han servido para obtener galardones como el Premio Ondas 2012 y el Premio AERO 2014 a la innovación radiofónica. Entre sus proyectos destaca Pop pins, con la colaboración de una escritora zaragozana que crea mundos paralelos a través de la ficción radiofónica, la Red 3.0, una webserie radiofónica, que permite que los oyentes sean productores de contenidos, aportando sus líneas argumentales, o Híbridos sonoros, radiodocumentales transmedia, que se difunden en una web y con los que interacciona el usuario. También hay otros espacios de narrativa transmedia en España en géneros informativos, como Interactivos cope, reportajes que aparecen en la web de la emisora y mediante los que el oyente puede construir su propio itinerario para conocer la historia desde otra perspectiva. En otros países, la ficción de la narrativa radiofónica ya ha experimentado esta evolución, pero en España la radio pública, RNE, es la que ha logrado que la audiencia escuche podcasts transmedia relacionados con la ficción televisiva. La emisora pública estatal ya fue pionera en poner de moda los seriales radiofónicos en la época de la posguerra, que duraban una hora y se emitían de lunes a viernes, llegando a emitirse hasta ocho novelas diferentes a lo largo del día (Cases Gelos, 2017). Siempre vinculada a la ficción sonora, tras una época de casi inexistencia del radioteatro o ficción en las emisoras, la emisora pública logra en estos últimos tiempos que las radios convencionales del 


\section{DISERTACIONES}

ESTUDIOS

El papel del sonido en la comunicación: contribución, funciones y efectos

ISSN: $1856-9536$

Doi: http://dx.doi.org/10.12804/revistas.urosario.edu.co/disertaciones/a.6547

Volumen 12, Número 2 / Julio-diciembre 2019

Versión PDF para imprimir desde

http://revistas.urosario.edu.co/index.php/disertaciones

país avancen hacia la modernidad con estos nuevos formatos, planteando la necesidad de una modificación de la narrativa sonora (Guarinos, 2017). Para Dann (2014), es el podcast el que posibilita la creación de esas narrativas más extensas y favorece la creación del universo transmedia.

\section{Objetivos del estudio}

El objetivo principal de este estudio es realizar un análisis comparativo de los nuevos formatos de ficción en Podium Podcast y en RNE durante la temporada 2016-2017. Como objetivos secundarios destacamos los siguientes:

1. Analizar el contenido de los espacios de ficción de la plataforma Podium Podcast y los formatos transmedia de la emisora RNE.

2. Encontrar los rasgos distintivos que permiten vislumbrar la tipología.

\section{Metodología}

Este trabajo de investigación está basado en el estudio de casos de dos espacios de ficción sonora transmedia de RNE y dos espacios de ficción de Podium Podcast. Analizamos la primera temporada de estos cuatro espacios (2016-2017). Este análisis responde fundamentalmente a un enfoque metodológico cualitativo y cuantitativo, que pretende alcanzar conclusiones mediante lógica inductiva a través de los datos obtenidos tras la escucha de dichas producciones.

La técnica empleada es el análisis de contenido de los espacios radiofónicos por medio de la escucha de programas y del análisis de las plataformas o páginas web en las que se encuentran alojados dichos podcasts. Examinamos el contenido teniendo en cuenta las variables de la narrativa audiovisual (Moreno, 2003) y del lenguaje radiofónico (Balsebre, 1994), que utiliza Muela Molina (2012) en su análisis de la ficción en las cuñas publicitarias. Además de otras variables que son de utilidad para llevar a cabo el análisis comparativo, como las de distribución propuestas por Martínez Costa (2015, p.186) o la tipología de estructura narrativa de Gordillo (2008). Las variables de análisis son:

a. Temática: social, ciencia ficción, misterio, histórica, otras.

b. Duración: menos de 5 minutos, entre 5 y 15, más de 15 minutos.

c. Personajes: narrador según la tipología de Genette: autodiegético o que relata sus experiencias; homodiegético o personaje que cuenta la historia sin ser el personaje central; y narrador heterodiegético que cuenta la historia sin implicarse (García Jiménez, 1993, p. 117), actor que representa a personajes reales, monólogo del narrador y diálogo de actores.

d. Contexto: lugares reales, ficticios, sin escenario definido.

e. Música: ambiental o descriptiva (recrea un escenario), anímica (estado de ánimo), sin música.

f. Efectos de sonido: descriptivo (escenario), expresivo (estado de ánimo), narrativo (cuenta lo que sucede), ornamental (cuestión estética).

g. Lenguaje utilizado: sonoro, visual, audiovisual, textual, multimedia. 
h. Estructura narrativa: lineal simple (fiel a su cronología), lineal intercalada (se intercalan secuencias no cronológicas), in media res (en mitad de la historia), paralela (historias paralelas no conectadas), de contrapunto (historias que coinciden en algún punto), inclusiva (historia que contiene otra historia), de inversión temporal (ruptura del tiempo cronológico) (Gordillo, 2008).

i. Distribución: soporte tradicional: radio, televisión, prensa, revistas; soporte digital: web, aplicaciones; y soporte interactivo: selección de redes sociales apropiadas (Martínez Costa, 2015).

Tabla 1. Categorización de las variables

\begin{tabular}{|c|c|}
\hline \multicolumn{2}{|r|}{ Variables de análisis } \\
\hline Temática & Social, ciencia ficción, misterio, histórica, otras. \\
\hline Duración & Menos de 5 minutos, entre 5 y 15 y más de 15 . \\
\hline $\begin{array}{l}\text { Personajes } \\
\text { (García Jiménez, 1993) } \\
\text { (Muela Molina, 2012) }\end{array}$ & $\begin{array}{l}\text { Narrador: autodiegético, homodiegético, heterodiegético. } \\
\text { Personaje real, monólogo del narrador, diálogo de actores. }\end{array}$ \\
\hline $\begin{array}{l}\text { Contexto } \\
\text { (Moreno, 2003) }\end{array}$ & Lugares reales, ficticios, sin escenario definido. \\
\hline $\begin{array}{l}\text { Música } \\
\text { (Muela Molina, 2012) }\end{array}$ & $\begin{array}{l}\text { Ambiental o descriptiva } \\
\text { Anímica } \\
\text { Sin música }\end{array}$ \\
\hline $\begin{array}{l}\text { Efectos de sonido } \\
\text { (Balsebre, 1994) }\end{array}$ & $\begin{array}{l}\text { Descriptivo } \\
\text { Expresivo } \\
\text { Narrativo } \\
\text { Ornamental }\end{array}$ \\
\hline $\begin{array}{l}\text { Lenguaje } \\
\text { (Balsebre, 1994) }\end{array}$ & $\begin{array}{l}\text { Sonoro } \\
\text { Visual } \\
\text { Audiovisual } \\
\text { Textual } \\
\text { Multimedia }\end{array}$ \\
\hline $\begin{array}{l}\text { Estructura narrativa } \\
\text { (Gordillo, 2008) }\end{array}$ & $\begin{array}{l}\text { Lineal simple } \\
\text { Lineal intercalada } \\
\text { In media res } \\
\text { Paralela } \\
\text { De contrapunto } \\
\text { Inclusiva } \\
\text { De inversión temporal }\end{array}$ \\
\hline $\begin{array}{l}\text { Distribución } \\
\text { (Martínez Costa, 2015) }\end{array}$ & $\begin{array}{l}\text { Soporte tradicional: radio, televisión, prensa, revistas. } \\
\text { Soporte digital: web, aplicaciones. } \\
\text { Soporte interactivo: selección de redes sociales apropiadas. }\end{array}$ \\
\hline
\end{tabular}

Fuente: elaboración de la autora. 


\section{DISERTACIONES}

ESTUDIOS

\section{Análisis de casos}

\section{El gran apagón y Negra y criminal de Podium Podcast}

El gran apagón es la serie revelación y la primera de ficción de Podium Podcast. Su temática es la ciencia ficción y narra qué ocurriría en un mundo sin tecnología tras sufrir un apagón solar. Cuenta con narrativas y tramas parecidas a las de las series de ficción televisivas. En esta primera temporada, un narrador heterodiegético relata la historia como si fuera un documental. Se suceden ocho capítulos en el que intervienen varios personajes, entre ellos un padre y su hija atrapados en la costa gallega, un bloguero, un físico, un funcionario de prisiones que sobrevive a un motín, militares de dudosa reputación, además de grabaciones presentadas como reales con entrevistas, podcasts, mensajes oficiales o comunicaciones entre radioaficionados. Podríamos decir que cada capítulo relata historias que tienen continuidad en otros capítulos, pero que se van alternando y presentando a diversos personajes que cuestionan el papel de las administraciones ante una situación límite. La duración media oscila entre los 12 y los 22 minutos, sigue el mismo patrón que los podcasts estadounidenses, marcado por Serial, que definió este tipo de productos sonoros y su modelo de consumo con los "early adopters que descubren algo nuevo para luego compartir esa experiencia con otros mediantes su recomendación personal” (Linares \& Neira, 2017, p. 77). Se trata de historias que se comparten en redes sociales y otros foros, y mantienen la atención del público semana tras semana. En Estados Unidos se refieren al commuting, tiempo medio que tardan en ir al trabajo, por ello la estructura y duración de los capítulos se conforman para entretener al oyente en este intervalo de tiempo. Cada capítulo presenta una media de 3 a 5 personajes principales. Los lugares que presentan son reales, con música anímica y efectos de sonido narrativos. El lenguaje es sonoro, aunque con evocaciones visuales, se centra en la descripción de los acontecimientos, ambientes, situaciones que refleja a través de la música y los efectos de sonido con planos sonoros que nos llevan a imaginar cada una de las escenas y secuencias de la serie. La estructura narrativa es de contrapunto, según la clasificación de Gordillo (2008), ya que son varias historias que tienen en común algo y coinciden en algún punto. La distribución es el soporte digital, la plataforma de Podium Podcast.

Tabla 2. El gran apagón (temporada 1)

\begin{tabular}{|c|c|}
\hline \multicolumn{2}{|c|}{ El gran apagón - Podium Podcast } \\
\hline Capítulos & Duración \\
\hline 1. La tormenta & $15^{\prime}: 23^{\prime \prime}$ \\
\hline 2. Atrapados & $15^{\prime}: 50^{\prime \prime}$ \\
\hline 3. Las llamadas & $09^{\prime}: 38^{\prime \prime}$ \\
\hline 4. El rescate & $19^{\prime}: 00^{\prime \prime}$ \\
\hline 5. La mitad oscura & $14^{\prime}: 39^{\prime \prime}$ \\
\hline 6. La modelo & $17^{\prime}: 16^{\prime \prime}$ \\
\hline 7. Escenario cero & $14^{\prime}: 51^{\prime \prime}$ \\
\hline 8. El museo & $22^{\prime}: 42^{\prime \prime}$ \\
\hline
\end{tabular}

Fuente: elaboración de la autora. 


\section{DISERTACIONES}

ESTUDIOS

El papel del sonido en la comunicación: contribución, funciones y efectos

ISSN: $1856-9536$

Doi: http://dx.doi.org/10.12804/revistas.urosario.edu.co/disertaciones/a.6547

Volumen 12, Número 2 / Julio-diciembre 2019

Versión PDF para imprimir desde

http://revistas.urosario.edu.co/index.php/disertaciones

Negra y criminal es una serie de podcast de suspense, miedo y crimen. Un espacio que se concibió para la madrugada de los sábados en la Cadena SER, pero que ha llegado a convertirse en otro de los espacios indispensables de la plataforma. Su duración oscila entre 30 y 40 minutos. Dirigido por la periodista Mona León Siminiani, en los nueve capítulos de la primera temporada relata crímenes reales con dramatizaciones, de gran calidad, con las voces de actores de doblaje. La periodista Mona León es la narradora heterodiegética que cumple esta función por encima de su labor de periodista. Fragmentos documentales reales con dramatizaciones se mezclan en los programas monográficos y los relatos son autoconclusivos o por entregas. Estas dramatizaciones se mezclan con la documentación enriquecida por entrevistas de la periodista e investigadora Mónica González Álvarez, quien hace alusión a casos reales con testimonios inquietantes. Los efectos son narrativos y ornamentales, a veces sirven como transiciones entre los documentos sonoros reales y la ficción. El lenguaje es sonoro, pero con una parte visual muy importante. Mona define este podcast como una nueva forma de hacer cine. La estructura narrativa es muy variada, a veces de inversión temporal (desde el final al principio de la historia), otras veces lineal simple (narra la historia de forma cronológica), inclusiva (incluye otras historias) y lineal intercalada (se intercalan secuencias que rompen con esa linealidad). Su difusión es, en esta temporada analizada, a través de la plataforma de forma exclusiva.

Tabla 3. Negra y criminal (temporada 1)

\begin{tabular}{|l|c|}
\hline \multicolumn{1}{|c|}{ Capítulos } & \multicolumn{1}{|c|}{ Degra y criminal - Podium Podcast } \\
\hline 1. Caso real - El horror construido: H. H. Holmes & $37^{\prime}: 21^{\prime \prime}$ \\
\hline 2. Ficción - El autoengaño: el discípulo del diablo & $40^{\prime}: 25^{\prime \prime}$ \\
\hline 3. Caso real - El peligro: el asesino de la baraja & $26^{\prime}: 49^{\prime \prime}$ \\
\hline 4. Caso real - La amabilidad: el estrangulador de Boston & $34^{\prime}: 18^{\prime \prime}$ \\
\hline 5. Ficción: la importancia de llamarse Sherlock Holmes - Los bailarines & $37^{\prime}: 36^{\prime \prime}$ \\
\hline 6. Caso real - El anhelo: el caso de Ed Gein & $36^{\prime}: 44^{\prime \prime}$ \\
\hline 7. Ficción - El objeto de deseo: la entrada & $42^{\prime}: 27^{\prime \prime}$ \\
\hline 8. Caso real - La fuerza y la debilidad: el secuestro de la farmacéutica de Olot & $40^{\prime}: 13^{\prime \prime}$ \\
\hline 9. Ficción - Vértigo & $57^{\prime}: 48^{\prime \prime}$ \\
\hline
\end{tabular}

Fuente: elaboración de la autora.

\section{Carlos de Gante y El ministerio del tiempo en RNE}

Carlos de Gante es una ficción sonora que a través de cinco capítulos recrea una conversación entre el emperador Carlos y Francisco de Borja en 1557. Su temática es histórica, basada en la exitosa serie Carlos, el emperador, que ha emitido la primera cadena de tve, la televisión pública, y aporta nuevos datos de los personajes históricos. Esta ficción rememora el reinado de uno de los reyes más importantes de la historia española y recuerda la infancia y primera juventud del emperador en el monasterio jesuita de Yuste tras la abdicación del rey al trono español. 


\section{DISERTACIONES}

ESTUDIOS

El papel del sonido en la comunicación: contribución, funciones y efectos

ISSN: 1856-9536

Doi: http://dx.doi.org/10.12804/revistas.urosario.edu.co/disertaciones/a.6547

Volumen 12, Número 2 / Julio-diciembre 2019

Versión PDF para imprimir desde

http://revistas.urosario.edu.co/index.php/disertaciones

Organizado por temáticas y fechas, cuenta la vida del rey desde su nacimiento en 1500 hasta 1517. La duración de sus episodios oscila entre los 6 y 7 minutos. Los personajes principales son el emperador Carlos y Francisco de Borja, quienes mantienen una conversación en cada uno de los capítulos evocando la infancia y juventud del emperador, además de las propias vivencias de Francisco de Borja. Aparte de la narración de los personajes, existe un narrador heterodiegético que sitúa al oyente en las fechas y lugares concretos a los que hace referencia la narración. El contexto son lugares reales, específicamente el monasterio de Yuste, donde tiene lugar la conversación entre los dos personajes principales; y Flandes, donde transcurre la infancia del emperador. La música tiene una función anímica y descriptiva, ya que intenta reflejar la gloria de los momentos históricos y se escuchan cánticos y coros religiosos propios del entorno donde se desarrolla la acción. Los efectos son descriptivos, como el crepitar de llamas, pasos, relinche y cabalgar de caballos. El lenguaje es sonoro, es un producto creado para ser escuchado, dando más importancia a la palabra que a los planos sonoros que recrean visualmente las escenas de los podcasts. La estructura narrativa es inclusiva, puesto que el relato, la conversación entre ellos, contiene otras historias relacionadas con el pasado de los personajes. La distribución es a través de la web de la radiotelevisión pública, RTVE, donde además se puede consultar el árbol genealógico de los personajes, sus biografías, y relacionarlas con los personajes de la serie televisiva.

Tabla 4. Carlos de Gante (temporada 1)

\begin{tabular}{|l|c|}
\hline \multicolumn{2}{|c|}{ Carlos de Gante - RNE } \\
\hline Capítulos & Duración \\
\hline 1. Hijo de rey & $07^{\prime}: 29^{\prime \prime}$ \\
\hline 2. Mujeres en el poder & $06^{\prime}: 41^{\prime \prime}$ \\
\hline 3. Matar al padre & $05^{\prime}: 56^{\prime \prime}$ \\
\hline 4. Príncipe y caballero & $07^{\prime}: 21^{\prime \prime}$ \\
\hline 5. El tablero de Europa & $06^{\prime}: 07^{\prime \prime}$ \\
\hline
\end{tabular}

Fuente: elaboración de la autora.

La serie El ministerio del tiempo es una producción de Televisión Española, que narra las historias de un organismo público oculto que se preocupa por mantener la integridad de los acontecimientos ocurridos en la historia de España. En la primera temporada, sus creadores consiguieron el objetivo de llegar a una audiencia muy entregada a la trama a través del programa web La puerta del tiempo, el foro de debate histórico y las redes sociales, Facebook, Twitter, Instagram y WhatsApp. En la segunda, la estrategia transmedia ha logrado ir más allá con la difusión del podcast Tiempo de valientes en RNE y debido a su éxito han seguido con la fórmula de la serie de podcast para la tercera temporada. Tiempo de valientes es un spin-off que narra las aventuras de Julián, uno de los personajes principales, fuera del ministerio. Los seis episodios de Tiempo de valientes tienen una duración entre los 2 y 3 minutos. La temática es ciencia ficción, aunque utiliza este género para realizar un recorrido por efemérides de la historia mundial y presentar a personajes relevantes que marcaron diversos acontecimientos de manera internacional. El personaje principal es Julián Martínez, quien a su vez es un narrador autodiegético que cuenta sus propias experiencias 


\section{DISERTACIONES}

\section{ESTUDIOS}

en Filipinas. La narración de Julián Martínez se basa en sus propios pensamientos, reflexiones y recuerdos, que complementan la trama de las aventuras de este personaje en la serie de televisión. El lugar que recrea es real, igual que la fecha del acontecimiento en el que el personaje emite estas reflexiones, en 1899, cuando un destacamento español fue sometido por los insurrectos filipinos en la iglesia del pueblo de Baler. En este caso la música también es descriptiva y sirve de transición entre las acciones que se desarrollan en el lugar y los propios pensamientos del personaje-narrador. El protagonista no interactúa con otros personajes, salvo en una ocasión en la que recibe una llamada de los funcionarios del ministerio del tiempo. Los efectos de sonido son narrativos: tiros, toses, llantos, sonido de móvil, escritura de pluma e incluso sonidos expresivos evocadores de pensamientos, como los del recuerdo de una escena de una película o un recuerdo de conversaciones con otros personajes del ministerio del tiempo. El lenguaje utilizado es sonoro por encima de la recreación visual. La estructura narrativa es lineal paralela, cronológica, aunque incluye recuerdos que son secuencias que rompen con esa linealidad. La distribución es a través de la web de RTVE, de forma exclusiva. Alojados en la web del ente público Radio Televisión Española, constituyen un paso más del fenómeno transmedia de la serie. Estos capítulos radiofónicos complementan la trama de la exitosa serie.

Tabla 5. Tiempo de valientes (temporada 1)

\begin{tabular}{|c|c|}
\hline \multicolumn{2}{|c|}{ Tiempo de valientes - RNE } \\
\hline Capítulos & Duración \\
\hline Capítulo 1 & $03^{\prime}: 43^{\prime \prime}$ \\
\hline Capítulo 2 & $03^{\prime}: 19^{\prime \prime}$ \\
\hline Capítulo 3 & $02^{\prime}: 43^{\prime \prime}$ \\
\hline Capítulo 4 & $03^{\prime}: 23^{\prime \prime}$ \\
\hline Capítulo 5 & $02^{\prime}: 31^{\prime \prime}$ \\
\hline Capítulo 6 & $02^{\prime}: 28^{\prime \prime}$ \\
\hline
\end{tabular}

Fuente: elaboración de la autora.

Destacamos en el análisis comparativo la diferencia entre personajes de los podcasts de RNE y Podium Podcast y la temática. Mientras que los podcasts de RNE tienen una temática histórica principalmente que refleja acontecimientos históricos en España con datos precisos, en los podcasts de Prisa se cuentan historias reales, pero también historias de ficción que obedecen más a la creatividad que a reflejar los hechos tal cual. Tal y como podemos ver en la figura 1, en los podcasts de RNE destaca el relato que realizan los narradores heterodiegético y autodiegético, mientras que en los podcasts del Grupo Prisa el narrador es heterediegético y se le da mayor importancia al diálogo de actores. 

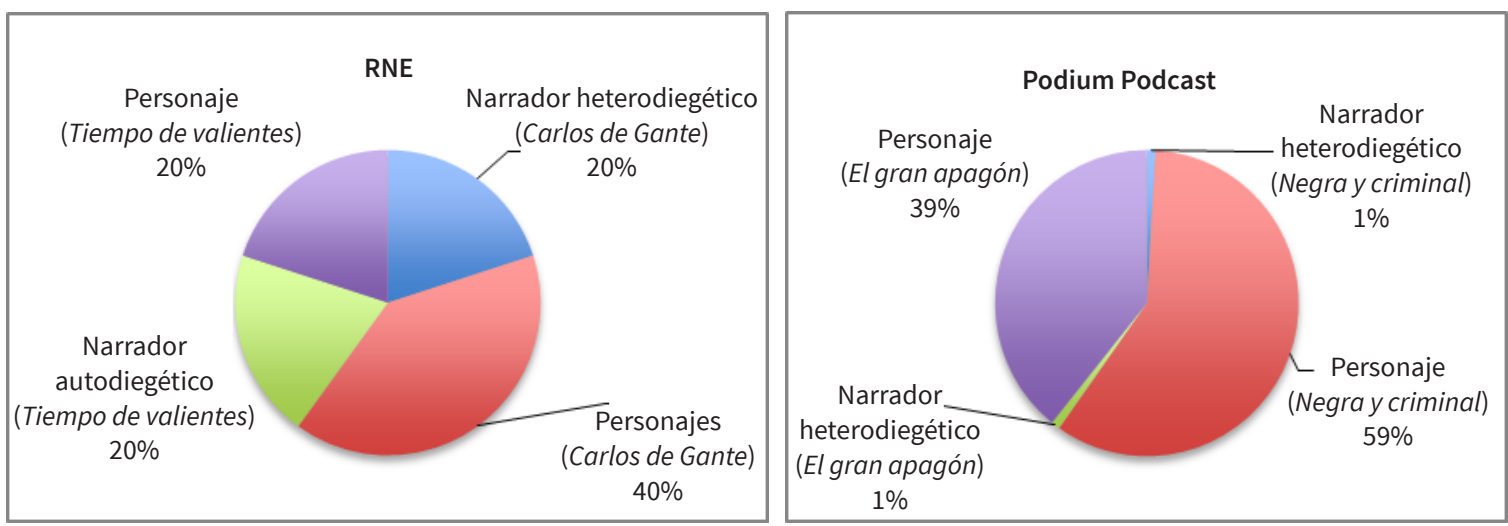

Figura 1. Diferencia entre número de personajes en RNE y Podium Podcast

Fuente: elaboración de la autora.

\section{Conclusiones}

Respondiendo al objetivo principal del análisis, detectamos entre las principales diferencias de los podcasts de RNE su duración, mucho más breve, de entre 2 y 5 minutos, frente a los podcasts de Podium Podcast, con una duración de entre 15 y 30 minutos. Los espacios de RNE son formatos que complementan la trama de las series televisivas, de forma que sin haber visto estas series no tienen toda la riqueza que presentan como parte del universo transmedia. Son relatos sonoros muy breves basados en pensamientos, reflexiones, que no dan prioridad a la acción. En el caso de Tiempo de valientes, con narrador autodiegético, expone estas experiencias en primera persona, la palabra es más importante que los planos visuales y se relaciona con tramas vividas con el personaje principal en la serie televisiva. El caso de Carlos de Gante se basa también en pensamientos, de nuevo el diálogo prima sobre las acciones e incluye fragmentos sonoros que se relacionan con la serie televisiva.

Por otra parte, Podium Podcast responde a la estructura del podcast estadounidense, pensado para su consumo en los trayectos de camino al trabajo como Serial. Son historias que enganchan al oyente porque utilizan estructuras narrativas de contrapunto y que suscitan interés e intriga capítulo a capítulo, como en algunas series televisivas. Es el caso de El gran apagón. Negra y criminal presenta casos aislados, historias que concluyen en cada capítulo. Cada uno puede tener diversas estructuras narrativas, muy atractivas para el receptor, pues relacionan testimonios reales y ficción, y el papel del narrador es muy importante como elemento conductor. La narradora es la periodista que a veces juega también un papel como personaje en el relato sonoro.

Como conclusión principal establecemos que son formatos novedosos que aportan un plus a otras tramas en otros soportes y medios, como se produce en las dos series de RNE. Además, la irrupción del podcast comercial en España, como es el caso de la plataforma Podium Podcast, rompe con la estructura tradicional del radioteatro, por su duración y por los elementos que utiliza con planos sonoros que recrean la acción como forma expresiva fundamental frente a la descripción. 


\section{DISERTACIONES}

ESTUDIOS

El papel del sonido en la comunicación: contribución, funciones y efectos

ISSN: $1856-9536$

Doi: http://dx.doi.org/10.12804/revistas.urosario.edu.co/disertaciones/a.6547

Volumen 12, Número 2 / Julio-diciembre 2019

Versión PDF para imprimir desde

http://revistas.urosario.edu.co/index.php/disertaciones

\section{Referencias}

1. AIMc. (2017). $3^{a}$ Ola del EGM. Madrid: Asociación para la Investigación de los Medios de Comunicación. Recuperado de https://www.aimc.es/blog/3a-ola-egm-streaming-supera-la-onda-media-la-escucha-radio/

2. Albarran, A. B., Anderson, T., Bejar, L. G., Bussart, A L., Daggett, E., Gibson, S., Gorman, M., Greer, D., Guo, M., Horst, J. L., Khalaf, T., Lay, J. P., McCracken, M., Mott, B. and Way, H. (2007). What happened to our audience? Radio and new technology uses and gratifications among young adult users. Journal of Radio Studies, 14(2) , $92-101$.

3. Balsebre, A. (1994). El lenguaje radiofónico. Madrid: Cátedra.

4. Balsebre, A. (1999). En el aire. 75 años de radio en España. Madrid: Promotora General de Revistas.

5. Cases Gelós, C. (2017). El auge de la ficción sonora en España mediante el podcasting (Trabajo de grado, Universidad Miguel Hernández, Elche).

6. Dann, L. (2014). Only half the story: radio drama, online audio and transmedia storytelling. Radio Journal: International Studies in Broadcast \& Audio Media, 12(1-2), 141-154.

7. Fernández Aldana, C. (marzo, 2015). Narrativa radiofónica transmedia. Un reto para la radio del siglo xxI. Ponencia presentada en el Congreso Internacional "Cultura digital, sociedad y comunicación: perspectivas en el siglo xxl", Universidad San Jorge, Zaragoza.

8. García Jiménez, J. (1993). Narrativa audiovisual. Madrid: Cátedra.

9. Gordillo Álvarez, I. (2008). El cine de senderos bifurcados: propuesta metodológica para el análisis narrativo del discurso de historias múltiples. Guiónactualidad.

10. Guarinos, V. (2017). La ficción monumental de la radio actual en España. Las adaptaciones sonoras cinematográficas. Revista de la Asociación Española de Investigación de la Comunicación, 4(7), 137-148.

11. Jenkins, H. (2006). Convergence culture. Where old and new media collide. Nueva York: University Press.

12. Jenkins, H. (2007). Transmedia storytelling 101. Confessions of an Aca-Fan. Recuperado de http://henryjenkins.org/2007/03/transmedia_storytelling_101.html

13. Linares de Palomar, R., \& Neira Borrajo, E. (2017). Serial, el programa radiofónico que resucitó el podcasting/ Serial, the radio programme that brought podcasting back to life. Area Abierta, 17(1), 73-82.

14. López, N., Medina, E., \& González, P. (mayo, 2011). Tendencias de consumo televisivo en jóvenes de 14 a 25 años: hacia el entretenimiento "cool". Ponencia presentada en el IV Congreso Internacional sobre Análisis Fílmico: "Nuevas tendencias e hibridaciones de los discursos audiovisuales en la cultura digital contemporánea”, Universitat Jaume I, Castellón.

15. López Vidales, N., Rubio, G., \& Rubio García, M. (2015). La radio de las nuevas generaciones de jóvenes españoles: hacia un consumo on line de música y entretenimiento. zER-Revista de Estudios de Comunicación, 19(37), 45-64.

16. Martínez Costa, M. D. (2015). Radio y nuevas narrativas: de la crossradio a la transradio. Radio, Sound and Internet, 168-187.

17. Moreno Cazalla, L. (2017). Podium Podcast, cuando el podcasting tiene acento español. Prisma Social: Revista de Investigación Social, (18), 334-364. 
18. Moreno, I. (2003). Narrativa audiovisual publicitaria. Barcelona: Paidós.

19. Muela Molina, C. (2012). La representación de la ficción en la cuña publicitaria. Personajes, contextos y otros elementos narrativos. Área Abierta. Revista de Comunicación Audiovisual y Publicitaria, 12(1), 1-15.

20. Phillips, A. (2012). A creator's guide to transmedia storytelling: how to captive and engage audience across multiple platforms. Nueva York: McGraw-Hill Professional.

21. Rodero Antón, E. (2004). Clasificación y caracterización de los géneros radiofónicos de ficción: los contenidos olvidados. En N. Mínguez \& N. Villagra, N. (Coords.), La comunicación: nuevos discursos y perspectivas (pp. 145-154). Madrid: Edipo.

22. Rodero Antón, E. (2005). Recuperar la creatividad radiofónica: razones para apostar por la radio de ficción. Anàlisi: Quaderns de Comunicació i Cultura, (32), 133-146.

23. Rodríguez Pallares, M. (2017). Reutilización de la ficción sonora en la Cadena SER. El caso de Podium Podcast/ Reusing of radio drama in Cadena SER. The case of Podium Podcast. Área Abierta, 17(1), 83.

24. Scolari, C. A. (2013). Narrativas transmedia: cuando todos los medios cuentan. Barcelona: Deusto. 